\title{
How will climate alter efficiency objectives? Simulated impact of using recent versus historic european weather data for the cost-optimal design of nearly zero energy buildings (NZEBs)
}

\author{
Delia D’Agostino ${ }^{1}$ and Danny S. Parker ${ }^{2}$ \\ ${ }^{1}$ European Commission, Joint Research Centre (JRC), Ispra, Italy \\ ${ }^{2}$ Florida Solar Energy Center, University of Central Florida, Cocoa, FL, USA
}

\begin{abstract}
Achieving "nearly zero energy buildings" (NZEB) has been established as a vital objective over the next decade within the European Union (EU) $[1,2]$. Previous work has shown that a series of very cost effective thermal efficiency measures, equipment, appliance and renewable energy choices are available across climates to reach the NZEB objective. Resulting detailed energy and economic optimization findings have been obtained and published $[3,4]$. One area that has just begun to be explored, however, is how selection of weather files and their application against coming climate change can influence outcomes from energy optimization procedures.
\end{abstract}

\section{Introduction}

Until now, many energy based simulations have used International Weather for Energy Calculations (IWEC or IWEC2) hourly weather files which represent average weather observed or TMY - typical metrological year-typically over the last 15-25 years [5]. The IWEC for Milan-Malpensa airport in Northern Italy represents data from 1984-2001. The more recent IWEC2 represents similar data for 1994-2011. However, over the last several years, a series of highly unusual weather has been experienced in Europe relative to historic norms. This weather has featured more extreme events, both in winter and summer-with temperatures up to $35 \mathrm{C}$ with average temperatures nearly $1 \mathrm{C}$ greater than longterm average. These extremes, short period of intense cold or heat, are likely to have significant impacts on both heating and cooling loads as well as best efficiency measures to reduce energy use to reach NZEB. Not only are heating and cooling budgets increased, but also extreme summer heat waves, such as that experienced in Italy in 2003, are associated with increased mortality among the elderly [6].

Recently, more up to date TMYs have become available, including data since 2011 with re-analysis based on satellite date [7]. Still, such data has the problem within the climate change already being experienced of looking backward for weather while projecting building energy use into the future. Thus, relying on past weather data in a rapidly changing climate domain is likely not the best strategy for designing NZEBs that will house people in the uncertain future [8]). Moreover, Amélie and Kummert [9] show that designing buildings for zero energy using outdated weather data can lead to missing energy savings targets in future years compared to considering "morphed" weather data files using the downscaling methods proposed by Bechler et al [10]. The basic problem is one of anticipating the future climate conditions when using historical weather data to evaluate the building energy use within simulations. From simulations, energy use is often projected out with economic assumptions by 30-50 years. This is acceptable if weather data is relatively stable with little change over long intervals. However, during periods of increasing climate change, relying on such data may produce misleading indications [11].

\section{Evaluation Approach}

To explore the weather related issue with simulation analysis, we use the well-accepted EnergyPlus model as implemented in the BEopt software model to evaluate this influence in Milan, Italy. The model performs detailed hourly sequential simulations estimating annual heating, cooling and water heating energy as well resulting costs. The model also evaluated how to achieve NZEB designs at the lowest possible cost in a variety of climates. Questions explored:

- How does the recent much more variable weather data in the most recent year relate to the historical averages for the IWEC weather as well as a TMY weather file "morphed" to account for expected warming?

- In what fashion do the differences in recent weather and morphed weather files translate into the balance and magnitude of differing heating and cooling loads?

- How does the more extreme recent weather data relate to differences in the chosen measures from the energy-economic optimization? For instance, would low solar gain windows appear more attractive than the current preference for high solar gain glazing? 
We attempt to briefly address these questions and explore how the changes in climate might portend important implications for the NZEB targets established in the EU.

We used the standard prototype residential building used in previous analysis as a point of continuity as shown in Figure 1. This is a standard new home with 120 $\mathrm{m}^{2}$ of living space. We did make a significant change in the building characteristics, which was to assume that all electric heating would be required given the strong effort towards future electrification of the European residential sector and the use of renewable resources with which to satisfy building loads. An efficient heat pump was assumed for the analysis but unlike our previous evaluation, we simulated standard levels of insulation and air tightness so that the building would better represent a European building that was more sensitive to weather conditions while a strong prospect for energy savings from refurbishment.

\section{Changing Weather Patterns in Northern Italy}

Table 1 summarizes how the weather has changed against old IWEC files with historic weather profile against the hourly data from Malpensa airport for the last 15 years. We also compare the IWEC files against other more recent treatments: IWEC2, and 10 year TMY files (termed TYP for this classification) as well as TMY files

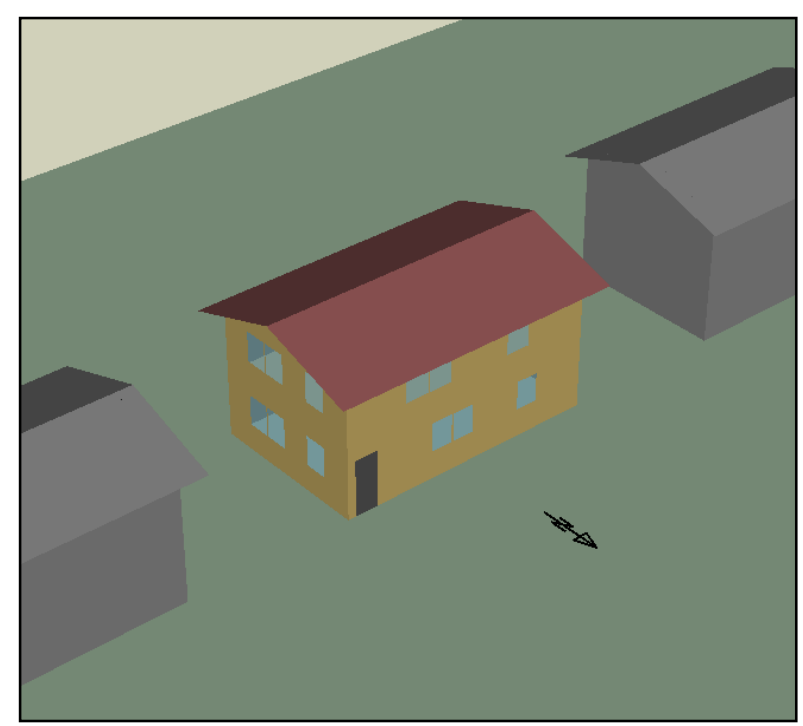

Figure 1. Prototype two story $120 \mathrm{~m}^{2}$ prototype building for climate sensitivity analysis as rendered for EnergyPlus

composed for the research project [12].

Note that the last ten years has shown an average temperature about $1.5 \mathrm{C}$ warmer than the 20 year average. Moreover, the last three years show an average increase of $2 \mathrm{C}$ or more. Perhaps more important are the summer hot weather events where the maximum outdoor temperature has been up to $3.7 \mathrm{C}$ warmer than the 19842001 weather. The last row represents data morphed from the TMY2003-2017 data to represent the year 2060 under expected climate conditions as will be described later.

Table 1. Weather Statistics for Milan-Malpensa over Historic IWEC Data vs. Recent Years

\begin{tabular}{|c|c|c|c|c|c|c|c|c|c|}
\hline 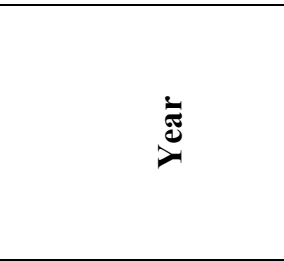 & 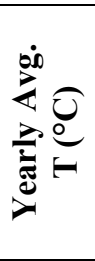 & 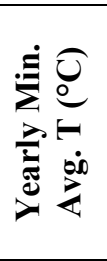 & 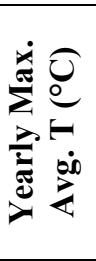 & 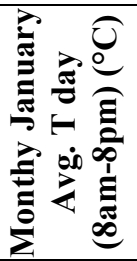 & 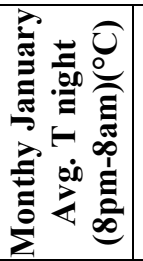 & 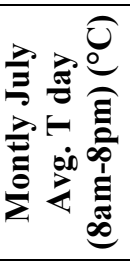 & 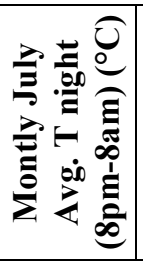 & 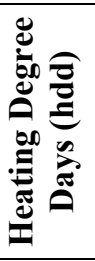 & 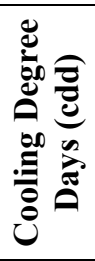 \\
\hline 2003 & 13.2 & -13.0 & 36.0 & 4.55 & -0.26 & 29.63 & 22.00 & 2710 & 763 \\
\hline 2004 & 12.1 & -8.4 & 34.0 & 3.74 & -0.34 & 25.65 & 19.35 & 2802 & 460 \\
\hline 2005 & 11.9 & -13.0 & 34.0 & 4.10 & -0.87 & 23.80 & 17.73 & 2879 & 479 \\
\hline 2006 & 12.3 & -13.0 & 35.0 & 1.84 & -4.28 & 23.52 & 17.52 & 2772 & 498 \\
\hline 2007 & 12.5 & -11.0 & 33.0 & 5.73 & 1.48 & 23.86 & 17.78 & 2663 & 469 \\
\hline 2008 & 12.5 & -9.0 & 32.0 & 5.17 & 1.11 & 26.07 & 19.72 & 2659 & 475 \\
\hline 2009 & 12.6 & -13.5 & 34.4 & 1.38 & -2.61 & 27.84 & 21.37 & 2764 & 608 \\
\hline 2010 & 11.8 & -13.0 & 33.0 & 1.85 & -0.65 & 24.70 & 19.04 & 2942 & 497 \\
\hline 2011 & 13.1 & -8.0 & 36.0 & 2.44 & -0.59 & 27.74 & 20.51 & 2555 & 594 \\
\hline 2012 & 12.8 & -18.0 & 35.0 & 4.48 & -1.32 & 28.87 & 21.57 & 2682 & 613 \\
\hline 2013 & 12.4 & -7.0 & 34.1 & 4.88 & 1.29 & 27.00 & 19.33 & 2746 & 520 \\
\hline 2014 & 13.2 & -8.0 & 33.0 & 5.87 & 2.19 & 22.78 & 17.85 & 2300 & 377 \\
\hline 2015 & 13.2 & -7.0 & 36.0 & 6.18 & 0.39 & 25.94 & 19.73 & 2537 & 614 \\
\hline 2016 & 13.2 & -9.7 & 32.4 & 5.01 & -0.51 & 26.23 & 19.84 & 2468 & 543 \\
\hline 2017 & 13.5 & -9.4 & 36.7 & 3.23 & -2.16 & 28.60 & 21.24 & 2501 & 686 \\
\hline IWEC: 1984-2001 & 11.2 & -11.2 & 33.0 & 2.20 & -2.28 & 24.72 & 17.18 & 3049 & 367 \\
\hline IWEC2: 1994-2011 & 12.2 & -10.0 & 32.6 & 4.67 & 0.66 & 25.90 & 19.46 & 2770 & 462 \\
\hline TYP2008-2017 & 12.7 & -11.0 & 32.7 & 5.80 & 1.39 & 25.08 & 19.36 & 2609 & 495 \\
\hline TMY2003-2017 & 12.7 & -8.4 & 34.0 & 3.74 & -0.34 & 26.06 & 19.70 & 2655 & 552 \\
\hline TYP2007-2016 & 12.2 & -6.6 & 31.5 & 5.09 & 1.90 & 24.30 & 19.88 & 2686 & 390 \\
\hline TMYShift-2060 & 16.0 & -5.1 & 38.1 & 6.29 & 2.29 & 31.10 & 24.18 & 1945 & 1084 \\
\hline
\end{tabular}


Figure 2 shows a plot of the hourly temperatures in Milan in the long-term weather file (green) against those experienced in 2017 (red). All 8760 hours are plotted with the daily amplitude in temperature readily observable in the peaks and valleys of each 24 hour period. Superimposed over this trend is the expected seasonal variation in temperature with the highest temperatures at mid-year during summer.

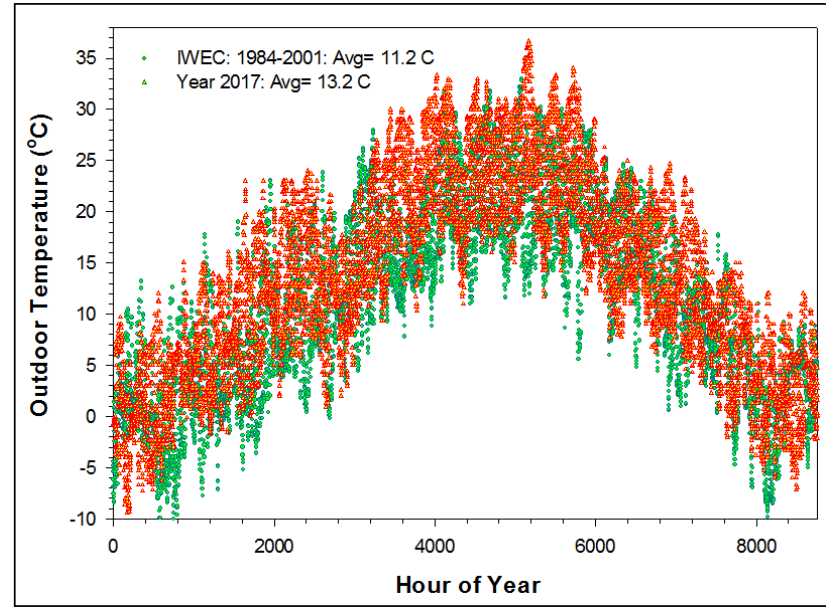

Figure 2. Hourly dry bulb temperatures in Milan in 18 year historic weather vs. Year 2017.

Focusing on the differences in Figure 2, it is seen that daily nighttime temperatures are considerably warmer in the 2017 data (red) as well as short periods of very hot data during the middle of the summer. However, the warming does not seem to extend to reduction of extreme winter weather. The extreme cold periods during winter mornings ( -9 to $-10 \mathrm{C}$ ) continue to be seen, although with shorter duration. Confining a statistical analysis to winter months (December - March) showed that the IWEC data was cooler $(2.5 \mathrm{C})$ against the average in 2017 (4.8 C). Differences in summer were even greater: $19.7 \mathrm{C}$ against $22.5 \mathrm{C}$ suggesting that the climate related warming being seen is concentrated in the summer months. Further examination of the hourly data during summer revealed that the average temperature differences between the long-term normal and the 2017 data were greatest between 10 PM and 7 $\mathrm{AM}(2.7 \mathrm{C}$ to $3.6 \mathrm{C})$. This reinforces the hypothesis that summer nights are warming most with climate change. These changes also have implications for cooling measures such as natural or forced nighttime ventilation.

Figure 3 shows the hourly plotted weather for Milan-Malpensa for the last fifteen years with that for the recent 2017 highlighted in red and the three previous years in orange. The older data is rendered in blues so that trends might be revealed to the eye. Again, it can be seen that the more recent data shows higher temperatures and less in the way of extreme winter temperatures in winter years. Similar to results previously discussed, nighttime temperatures each day look to be warmer in recent years than the early part of the time series.

The first four years of the data series was statistically compared with the last four years. A t-test of means showed that the average temperature in MilanMalpensa was warmer in recent years by $0.94( \pm 0.05) \mathrm{C}$, a conclusion statistically significant with a p-value of 0 .

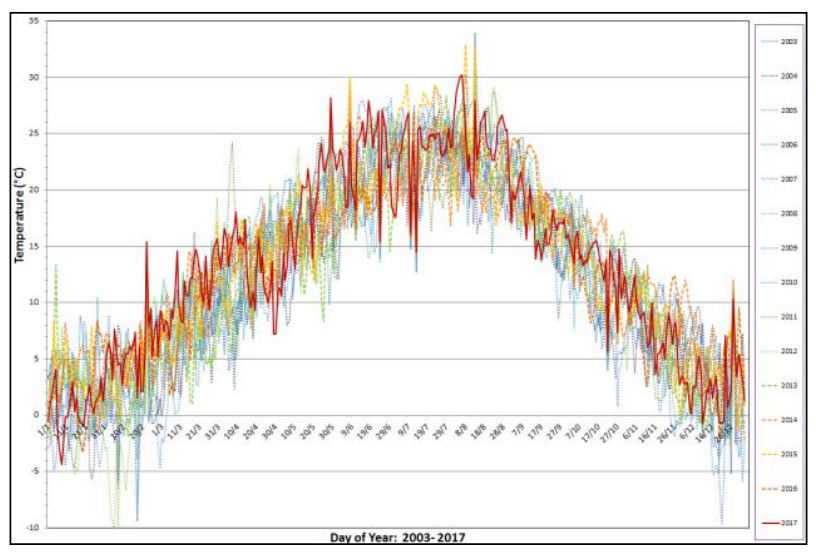

Figure 3. Hourly average dry bulb temperatures in Milan from 2003-2017 (2017 highlighted in red); three previous years in orange.

Figure 4 shows the cumulative distribution frequency (CDF) of drybulb temperature at MilanMalpensa as shown in the IWEC from 1984-2001 and each of the individual weather files from the last 15 years. However, based on climate projections for the IPCC $5^{\text {th }}$ assessment [13], we used the WeatherShift calculation [14] to "morph" our most recent 2003-2017 TMY file to anticipate the future climate in Northern Italy in the year 2060. The WeatherShift calculation allows selection of different greenhouse gas emission scenarios by the IPCC definitions [14]. This includes the Representative Concentration Pathways (RCP) and the various associated warming potential percentiles. For our exercise, we utilized the RCP 8.5 pathway-which largely represents business as usual, along with the $50 \%$ percentile level of anticipated warming. The file (TMYshift_2060) then represents the hourly weather for building energy simulation associated with this scenario. The resulting file suggests that the average temperature in Milan will rise to $16.0 \mathrm{C}$ by 2060 under those assumptions. This is approximately $4.8 \mathrm{C}$ higher than the average temperature in the 1984-2001 IWEC file and 2.3 $\mathrm{C}$ warmer even than the recent 2017 yearly data which was one of the hottest on record. This is useful as the CDF shows the hours experienced at particular temperature and demonstrates that the IWEC file is quite different both from the TMY 2003-2017 as well as the 2017 annual file which was one of the hottest on record. 


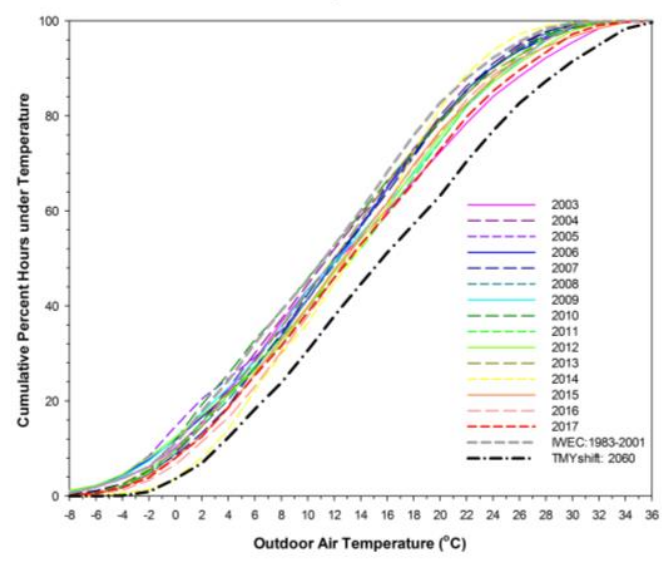

Figure 4. Cumulative Distribution Frequency of outdoor temperatures for Milan-Malpensa, 1984-2017 for each year, the IWEC file and a morphed TMY Weathershift file from 20032017.

Figure 5 shows the cumulative distribution frequency of the analyzed weather files: the 1984-2001 IWEC file, the WeatherShift TMY file for 2060 and the other files for selecting representative weather for building energy simulation for Milan-Malpensa. As a point of reference the annual weather file for 2017 is also included (red) showing how weather data for 2017 was halfway between the annual individual yearly weather files and the morphed TMYShift_2060 file.

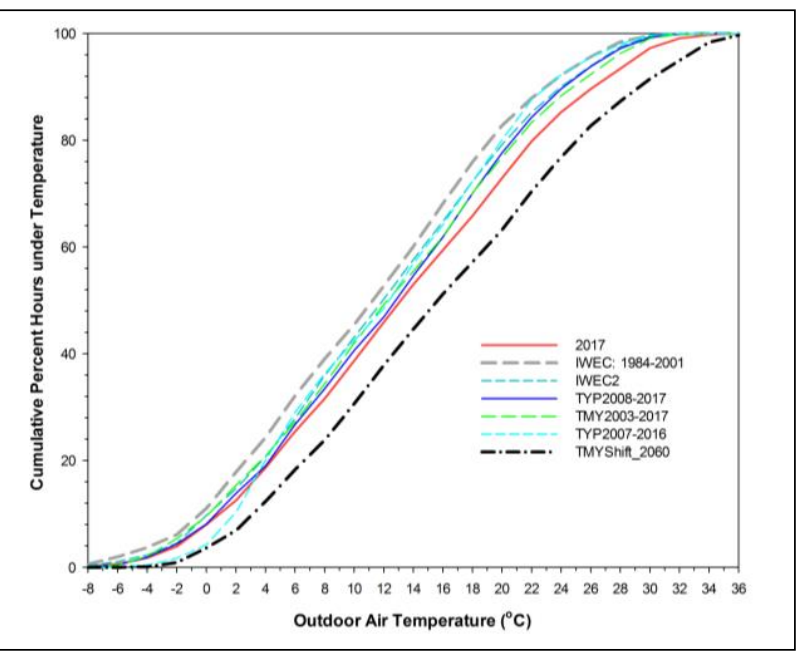

Figure 5: Cumulative Distribution frequency of outdoor temperatures for Milan-Malpensa for various available weather files including a TMYfile morphed to 2060 .

\section{Simulation Results}

Our evaluation of the historical IWEC weather data from 1984-2001 for Milan showed a dramatically altered balance of heating and cooling for our base prototype building. The predicted energy use for the long-term weather data is shown in Figure 6 (top of next page) against that predicted using the more recent weather patterns in 2017 as well as the morphed TMY file for 2060.
In reviewing Figure 6, we note that while total energy goes down due to the large reduction in total heating (light red), that cooling consumption (blue) more than doubles in 2017 against the IWEC average (1078 $\mathrm{kWh}$ vs. $393 \mathrm{kWh}$ ). Results for other each of the last fifteen years as well as the TYP and TMY files are shown below in Table 2 (on the next page).

We also track how the predicted PV production varies by year as predicted by the TRNSYS simulation from the weather files. These results suggest that the IWEC is so different from recent weather that that they should not even be used as a source for morphing files intended to be representative of the future. For instance, the IWEC was found to over predicting heating over the last fifteen years by $22 \%$, under-predict cooling by $76 \%$. Perhaps worst of all, the IWEC predicted 37\% lower solar PV output than the average predicted by the actual weather over the last 15 years. This is a key shortcoming given the importance of solar electric power production for estimating NZEB building performance.

The IWEC2 files, on the other hand, are a large improvement in predicting weather over the last fifteen years. The two TYP files covering ten year periods, one from White Box Technologies [15] and the other from Huld et al. [7] are both reasonable. Not surprisingly, a project TMY file composed from 2003-2017, provided the lowest deviations relative to all parameters of interest: heating, cooling, total and solar electric output. It should be kept in mind, however, that while the 15 year TMY file produced the lowest deviations in average computed heating and cooling loads in the past, and there is no guarantee that this would be true in a changing future with increasing outdoor temperatures. Indeed, this is precisely the challenge expressed by Amélie and Kummert [9] where simulated building performance accuracy in the future is likely constrained by the use of weather data linked to the past.

Our results showed that the balance of heating and cooling in Milan has already dramatically changed. For instance, simulating each individual year from 20032017 showed a reduction in the average heating needs by $22 \%$ over the 1984-2001 IWEC data while cooling increased by $76 \%$. The morphed 2060 weather data suggests this altered balance will become even more skewed in the future with cooling increasing by over a $100 \%$ while heating drops by $30 \%$. Given these influences, we then used EnergyPlus optimization to examine what they mean to achieving NZEB in Northern Italy. 

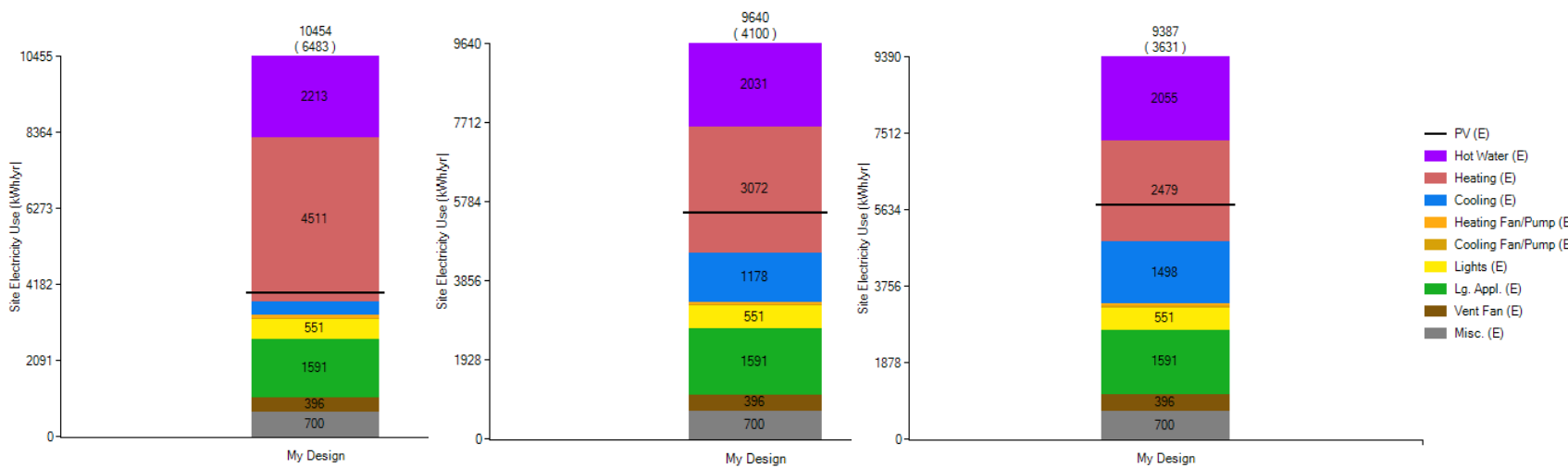

Figure 6. Predicted annual electricity by end-use with 1984-2001 average data for baseline building versus 2017 and then against the morphed TMY data for 2060. Results for Milan. Note reduction of heating (red), but large growth of cooling (blue)

Table 2. Simulated Impact of Weather Source Data on Balance of Heating and Cooling Milan, Italy: 2003- 2017.

\begin{tabular}{|c|c|c|c|c|c|c|c|c|}
\hline \multicolumn{4}{|c|}{ Existing Poorly Insulated Building } & \multirow{3}{*}{$\frac{\text { Solar PV }}{\underline{\text { kWh }}}$} & \multicolumn{4}{|c|}{ Variances from 15-Year Average } \\
\hline Year & Heating & Cooling & Total kWh & & Heat & Cooling 1 & Total kWh & Solar PV \\
\hline & kWh & kWh & Heat \& Cool & & Deviation & Deviation & Deviation & Deviation \\
\hline 2003 & 3526 & 1078 & 4604 & 5616 & $-0.1 \%$ & $55.8 \%$ & $9.1 \%$ & $3.2 \%$ \\
\hline 2004 & 3784 & 519 & 4303 & 5384 & $7.3 \%$ & $-25.0 \%$ & $2.0 \%$ & $-1.0 \%$ \\
\hline 2005 & 3787 & 525 & 4312 & 5515 & $7.3 \%$ & $-24.1 \%$ & $2.2 \%$ & $1.4 \%$ \\
\hline 2006 & 3593 & 492 & 4085 & 5499 & $1.8 \%$ & $-28.9 \%$ & $-3.2 \%$ & $1.1 \%$ \\
\hline 2007 & 3344 & 448 & 3792 & 5551 & $-5.2 \%$ & $-35.2 \%$ & $-10.1 \%$ & $2.1 \%$ \\
\hline 2008 & 3532 & 589 & 4121 & 5325 & $0.1 \%$ & $-14.9 \%$ & $-2.3 \%$ & $-2.1 \%$ \\
\hline 2009 & 3798 & 783 & 4581 & 5410 & $7.7 \%$ & $13.2 \%$ & $8.6 \%$ & $-0.5 \%$ \\
\hline 2010 & 4332 & 592 & 4924 & 5278 & $22.8 \%$ & $-14.4 \%$ & $16.7 \%$ & $-3.0 \%$ \\
\hline 2011 & 3406 & 721 & 4127 & 5402 & $-3.5 \%$ & $4.2 \%$ & $-2.2 \%$ & $-0.7 \%$ \\
\hline 2012 & 3625 & 870 & 4495 & 5296 & $2.7 \%$ & $25.8 \%$ & $6.5 \%$ & $-2.6 \%$ \\
\hline 2013 & 3886 & 610 & 4496 & 5074 & $10.1 \%$ & $-11.8 \%$ & $6.5 \%$ & $-6.7 \%$ \\
\hline 2014 & 2943 & 337 & 3280 & 5460 & $-16.6 \%$ & $-51.3 \%$ & $-22.3 \%$ & $0.4 \%$ \\
\hline 2015 & 3250 & 850 & 4100 & 5800 & $-7.9 \%$ & $22.9 \%$ & $-2.8 \%$ & $6.6 \%$ \\
\hline 2016 & 3042 & 785 & 3827 & 5441 & $-13.8 \%$ & $13.5 \%$ & $-9.3 \%$ & $0.0 \%$ \\
\hline$\underline{2017}$ & $\underline{3072}$ & $\underline{1178}$ & $\underline{4250}$ & $\underline{5540}$ & $-12.9 \%$ & $70.3 \%$ & $0.7 \%$ & $1.8 \%$ \\
\hline Avg: 2003-2017 & 3528 & 692 & 4220 & 5439 & & & & \\
\hline IWEC & 4511 & 393 & 4904 & 3971 & $27.9 \%$ & $-43.2 \%$ & $16.2 \%$ & $-27.0 \%$ \\
\hline IWEC2 & 3218 & 651 & 3869 & 5316 & $-8.8 \%$ & $-5.9 \%$ & $-8.3 \%$ & $-2.3 \%$ \\
\hline 2008-2017 TYP & 3312 & 677 & 3989 & 5314 & $-6.1 \%$ & $-2.1 \%$ & $-5.5 \%$ & $-2.3 \%$ \\
\hline 2007-2016 TYP & 3353 & 577 & 3930 & 5390 & $-5.0 \%$ & $-16.6 \%$ & $-6.9 \%$ & $-0.9 \%$ \\
\hline 2003-2017 TMY & 3464 & 733 & 4197 & 5466 & $-1.8 \%$ & $6.0 \%$ & $-0.5 \%$ & $0.5 \%$ \\
\hline TMYShift_2060 & 2479 & 1498 & 3977 & 5756 & $-29.7 \%$ & $116.5 \%$ & $-5.8 \%$ & $5.8 \%$ \\
\hline
\end{tabular}

\section{Selected Optimization}

We used the NREL BEopt software [16] which features an exhaustive optimization of the energy and economics of selected options powered by the EnergyPlus simulation engine. Within the simulations we started with a poorly insulated buidling in Milan-Malpensa which was then improved by the simulation scheme as more thoroughly described in our earlier efforts [2]. Two changes were important for this exercise. First was to change the building to an all-electric one to harmonize with current efforts in the EU to eliminate the consumption of fossil fuels. The second was to alter the cooling setpoints upwards to $24.4 \mathrm{C}$ as this had previously been set lower under the anticipation of a changing climate when using the older weather files.

In all optimizations, the following characteristics were seen in the results regardless of weather files used: Walls: 0.14-0.18 W/ $/ \mathrm{m}^{2}-\mathrm{K}$ conductance, Windows: Lowe with improved frame and argon fill, airtighness: 0.6 air 
changes per hour, with a $90 \%$ efficient enthalpy recovery ventilator ventilation system. All heating and cooling loads were served by ductless heat pumps with a COP of 7.4. Heat pump water heater, all $\mathrm{A}+++$ appliances and efficient lighting.

Similar to an analysis of building energy against morphed weather data done by Troup and Fannon [17] we showed that all more recent weather file data and particularly the morphed data reveal reduced heating loads and increased cooling loads. However, for Milan, the total energy use declined slightly, but with a large change in the balance of cooling against heating. The altered weather, if correct, would suggest that spring and autumn would exhibit considerably warmer conditions in Milan by 2060 under the IPCC RCP 8.5 scenario. Indicated peak summer temperatures are upwards to 38 C.

We found that the weather files, particularly the morphed data, had an influence on the optimal roof insulation to some extent, but with solar control becoming more important. The optimized simulation endpoints for weather sensitive elements are summarized for the various weather files within Table 3 .

This suggests that future conditions in Northern Italy will begin to emphasize building elements to reduce cooling needs. Although not shown, we did find that optimal appliances and lighting were selected earlier in the optimization process with the more recent weather files - reflecting the increase emphasis on reducing internal heat gains and their impact on cooling. Generally, our results mirrored those of Ferrara and Fabrizio [18], recommending lower levels of insulation within the warmer weather in more recent weather files-particularly with the morphed weather file reflecting possible future conditions. Perhaps most importantly, we found that optimizing the building envelope and airtightness and its equipment made it such that the optimized building in all cases was less sensitive to prevailing weather conditions than the less efficient baseline building.

However, we also showed increasing preference for lighter colored surfaces with higher reflectance for both roof and walls. Better solar control from windows (lower G-factor) were called for as well as an added emphasis in the early parts of the optimization process towards more efficient lighting and appliances that will reduce cooling needs from internal loads. Our results also showed that added energy efficiency is a hedge against climate change for occupants as the better insulated and optimized buildings also showed more resilence against temperature extremes and extreme weather events. The final energy use varied much less for the NZEB constructions than that of the baseline.

Table 3

Selection of Optimized Building elements depending on Source Weather Files Used

\begin{tabular}{|l|c|c|c|c|}
\hline $\begin{array}{c}\text { Milan-Malpensa } \\
\text { Weather File }\end{array}$ & $\begin{array}{c}\text { Optimal } \\
\text { Insulation }\end{array}$ & $\begin{array}{c}\text { Roof } \\
\text { Finish }\end{array}$ & $\begin{array}{c}\text { Window } \\
\text { G-Factor }\end{array}$ & $\begin{array}{c}\text { Wall } \\
\text { Finish }\end{array}$ \\
\hline IWEC (1984-2001) & $0.14 \mathrm{~W} / \mathrm{m}^{2}-\mathrm{K}$ & Dark & High-gain & Medium Dark \\
IWEC2 (1994-2011) & $0.14 \mathrm{~W} / \mathrm{m}^{2}-\mathrm{K}$ & Medium & High-gain & Medium Dark \\
$2003-2017 \mathrm{TMY}$ & $0.18 \mathrm{~W} / \mathrm{m}^{2}-\mathrm{K}$ & Medium & Low-gain & Medium Dark \\
2017 Extreme Year & $0.18 \mathrm{~W} / \mathrm{m}^{2}-\mathrm{K}$ & Light & Low-gain & Medium \\
Morphed TMY 2060 & $0.18 \mathrm{~W} / \mathrm{m}^{2}-\mathrm{K}$ & Light & Low-gain & Light \\
\hline
\end{tabular}

\section{Discussion and Conclusions}

A preliminary analysis examining older IWEC weather data (1984-2001) shows that these hourly data appear no longer adequate with which to analyze building energy efficiency options. Not only were temperature distributions not longer representative, but solar data, critical for evaluating NZEB photovoltaic performance was deficient as well. The IWEC2 was better, but a more recent TMY from 2003-2017 appeared superior relative to recent years. The extreme summer temperatures seen in Northern Europe may entering a "new normal" relative to coming years with implications for the balance of heating and cooling in dwellings. We showed that a prototypical residential building simulated in Milan, Italy saw relative annual heating go down by about $22 \%$ while cooling related energy use was increased by $76 \%$. Using a weather file morphed to 2060 to approximate expected climate related changes under the IPCC RCP 8.5 scenario, we found cooling increasing by nearly four times in Milan-Malpensa versus the IWEC historical data.

This change has implications for Passive House design where "summer bypass" ventilation and other cooling methods, both passive and active will be more important to successful designs. Due to the large impact of internal heat gains on summer overheating in well insulated buildings, low energy appliances and lighting will become even more important to reduce cooling needs or choice of mechanical cooling in marginal climates with climate change across Europe. 
We suggest that the new extreme, short period of intense cold or heat, are likely to have significant impacts on both heating and cooling loads as well as best efficiency measures to reduce energy use to reach NZEB. Analysis methods using most recent weather data or morphed weather data were shown to be critical for obtaining useful results. For instance, to obtain most appropriate optimal selections among technologies that have implications for cooling loads such as window type (heat gain characteristics) and building envelope finishes (solar reflectance properties). One practical suggestion in locations expecting to receive increased future cooling loads is that medium height vegetation around facades or extended balconies, awnings or shutters may be helpful in reducing wall/window solar gains while not interrupting rooftop solar irradiance where distributed photovoltaics will likely be of greater importance in the future.

\section{Acknowledgements}

We appreciate the combined support of Dr. Christian Thiel at the Joint Research Centre and Dr. James Fenton, at the University of Central Florida/ Florida Solar Energy Center, to support this collaborative research. Drury Crawley (Bentley Systems) and Linda Lawrie were instrumental in obtaining extensive weather files upon which we were able to use for the analysis. Joe Huang with White Box Technologies provided additional files and suggestions.

\section{References}

[1] Delia D'Agostino, “Assessment of the progress towards the establishment of definitions of Nearly Zero Energy Buildings (NZEBs) in European Member States, Journal of Building Engineering, 1 (2015), pp. 20-32, https://doi.org/10.1016/j.jobe.2015.01.002.

[2] Delia D'Agostino, Livio Mazzarella, What is a Nearly zero energy building? Overview, implementation and comparison of definitions, Journal of Building Engineering $21 \quad$ (2019) 200-212, https://doi.org/10.1016/j.jobe.2018.10.019

[3] Delia D'Agostino and Danny Parker, “A Framework for the cost optimal design of Nearly Zero Energy Buildings (NZEBs) in representative Climates across Europe," Energy, Vol. 149, 15 April 2018, https://doi.org/10.1016/j.energy.2018.02.020.

[4] D'Agostino, D., Parker, D., Data on cost-optimal Nearly Zero Energy Buildings (NZEBs) across Europe. Data Brief (2018b). https://doi.org/10.1016/j.dib.2018.02.038.

[5] ASHRAE. 2001. International Weather for Energy Calculations (IWEC and IWEC2 Weather Files) Users Manual and CD-ROM, Atlanta: American Society of Heating, Refrigerating and Air Conditioning Engineers.
[6] S. Conti, P. Meli, G. Mellini, R. Solimini, V. Toccaceli, M. Vichi, C. Beltrano and L. Perini, "Epidemiologic Study of Mortality during the Summer 2003 Heat Wave in Italy," Environ Res, 2005, Jul; 98(3): 390-9.

[7] Thomas Huld, Elena Paietta, Paolo Zangheri and Irene Pinedo Pascua, "Assembling Typical Meteorological Year Data Sets for Building Energy Performance Using Reanalysis and Satellite Based Data," Atmosphere, 2018, 9, 53.

[8] Peter de Wilde, "The Implications of a Changing Climate for Buildings," Building and Environment, 55, (2012), pp.1-7.

[9] Robert Amélie and Michäel Kummert, "Designing Net Zero Energy Buildings for the Future Climate, not for the Past," Building and Environment, 55, (2012), pp.150-158.

[10] S.E. Belcher, J.N. Hacker and D.S. Powell, "Constructing Design Weather Data for Future Climates, Building Serv. Eng. Res Technol 26, (2005), pp. 49-61.

[11] Drury B. Crawley, "Creating Weather File for Climate Changes and Urbanization Impacts: Proceedings of Building Simulation 2007, Beijing, China, IBPSA, Volume: pp. 1075-1082

[12] Drury B. Crawley and Linda Lawrie, "MY and TMY Files: Milan-Malpensa, Italy, 1966-2017," Bentley Systems, December 2018, https://www.bentley.com/en.

[13] IPCC, 2014. Climate Change 2014: Synthesis Report, $5^{\text {th }}$ Assessment Report of the Intergovernmental Panel on Climate Change, R.K. Pachauri and I.A. Meyer (eds.), IPCC, Geneva, Switzerland.

[14] WeatherShift, www.weathershift.com

[15] Joe Huang, "TYP file for Milan-Malpensa, Italy," White Box Technologies, Moraga, CA, 2018.

[16] C. Christensen, S. Horowitz, T. Givler, G. Barker, A. Courney, BEopt: software for identifying optimal building designs on the path to zero net energy, NREL/CP-550-3733, National Renewable Energy Laboratory, Golden, CO (2005)

[17] Luke Troup and David Fannon, "Morphing Climate Data to Simulate Building Energy Consumption," ASHRAE and IBPSA-USA SimBuld 2016 Building Performance Modeling Conference, Salt Lake City, UT, August 8-12, 2016

[18] Maria Ferrara and Enrico Fabrizio, "Cost Optimal NZEBs in Future Climate Scenarios," CISBAT 2017 International Conference, Lausanne, Switzerland, 6-8 September 2017. 